\title{
A possible cause of the AO polarity reversal from winter to summer in 2010 and its relation to hemispheric extreme summer weather
}

\author{
Yuriko Otomi · Yoshihiro Tachibana • \\ Tetsu Nakamura
}

Received: 7 February 2012/ Accepted: 26 April 2012/Published online: 16 May 2012

(C) The Author(s) 2012. This article is published with open access at Springerlink.com

\begin{abstract}
In 2010, the Northern Hemisphere, in particular Russia and Japan, experienced an abnormally hot summer characterized by record-breaking warm temperatures and associated with a strongly positive Arctic Oscillation (AO), that is, low pressure in the Arctic and high pressure in the midlatitudes. In contrast, the AO index the previous winter and spring (2009/2010) was record-breaking negative. The AO polarity reversal that began in summer 2010 can explain the abnormally hot summer. The winter sea surface temperatures (SST) in the North Atlantic Ocean showed a tripolar anomaly pattern-warm SST anomalies over the tropics and high latitudes and cold SST anomalies over the midlatitudes-under the influence of the negative AO. The warm SST anomalies continued into summer 2010 because of the large oceanic heat capacity. A model simulation strongly suggested that the AO-related summertime North Atlantic oceanic warm temperature anomalies remotely caused blocking highs to form over Europe, which amplified the positive summertime AO. Thus, a
\end{abstract}

Y. Otomi · Y. Tachibana $(\bowtie)$

Climate and Ecosystem Dynamics Division,

Mie University, Tsu, Japan

e-mail: tachi@bio.mie-u.ac.jp

Y. Tachibana

Japan Agency for Marine-Earth Science

and Technology, Yokosuka, Japan

T. Nakamura

Center for Global Environmental Research,

National Institute for Environmental Studies,

Tsukuba, Japan

T. Nakamura

Faculty of Environmental Earth Science,

Hokkaido University, Sapporo, Japan possible cause of the $\mathrm{AO}$ polarity reversal might be the "memory" of the negative winter AO in the North Atlantic Ocean, suggesting an interseasonal linkage of the $\mathrm{AO}$ in which the oceanic memory of a wintertime negative AO induces a positive $\mathrm{AO}$ in the following summer. Understanding of this interseasonal linkage may aid in the longterm prediction of such abnormal summer events.

Keywords AO - Hot summer $2010 \cdot$ NAM . Atlantic SST · Blocking

\section{Introduction}

In Japan, summer 2010 was the warmest in about 100 years of countrywide measurement records. Moreover, summer 2010 was abnormally hot on a planetary scale. For example, Europe, especially Eastern Europe and western Russia, experienced record-breaking hot temperatures, attributed to strong atmospheric blocking over the Euro-Russian region from late June to early August (Matsueda 2011). Additionally, Barriopedro et al. (2011) showed that the spatial extent of the record-breaking temperatures of summer 2010 exceeded the area affected by the previous hottest summer of 2003. Heat anomalies covered almost the entire Eurasian continent in 2010. In contrast, in winter 2009/2010, just a half-year earlier, the continent suffered from anomalously cold weather associated with a record-breaking negative Arctic Oscillation (AO), which is characterized by positive sea level pressure anomalies over the Arctic and negative pressure anomalies over the midlatitudes (Thompson and Wallace 2000). Moreover, in the same winter, a recordbreaking negative North Atlantic Oscillation (NAO) caused several severe cold spells over northern and western Europe (Cattiaux et al. 2010). In fact, the strongest 
negative AO index of the past 30 years was observed in December 2009 (Wang and Chen 2010). This drastic reversal from a record-breaking cold winter to a recordbreaking hot summer is preserved in our memory. What if, however, that memory could be preserved not only in our minds but also somewhere on the earth? In particular, might a memory of the strongly negative wintertime 2009/2010 AO have been preserved in the ocean, because of its large thermal heat capacity, which could then be recalled the following summer?

The winter-to-summer evolution of the AO index during 2009/2010 can be summarized as follows: a strongly negative wintertime AO index continued until May, after which it abruptly changed, becoming strongly positive in July and continuing so until the beginning of August. Details of the AO evolution will be described in the following sections. Ogi et al. (2005) pointed out that a strongly positive summertime $\mathrm{AO}$ is associated with occurrences of blocking anticyclones, which contributed to the abnormally hot European summer. Trigo et al. (2005) also reported that a blocking anticyclone caused the anomalous hot summer of 2003. The blocking anticyclone over Europe in summer 2003 was shown to be part of a planetary-scale wave train, extending from Europe to eastern Eurasia (Orsolini and Nikulin 2006). The abrupt change of the AO index from strongly negative to strongly positive in 2010 thus corresponded to the change from the abnormally cold winter of 2009/2010 to the abnormally hot summer of 2010, which shows that the AO index is a good indicator of abnormal weather on a planetary-scale, and that extra-seasonal prediction of the $\mathrm{AO}$ is a key to long-term forecasting. In this study, we therefore aimed to examine the cause of the 2010 change in the AO from strongly negative to strongly positive.

\section{Data and method}

The AO was first defined by Thompson and Wallace (2000) which is based on an invariant empirical orthogonal function (EOF) spatial pattern throughout the year, and Ogi et al. (2004) identified seasonal variations of the Northern Hemisphere annular mode (SV NAM) from 1958 to 2002 by performing an EOF analysis. EOF was applied to a temporal covariance matrix of geopotential height fields for individual calendar months using a zonally averaged monthly geopotential height field from 1,000 to $200 \mathrm{hPa}$ for the area poleward of $40^{\circ} \mathrm{N}$. The daily time series of the SV NAM index is obtained by projecting daily zonal mean geopotential height anomalies onto the EOF of each month. The time series of the SV NAM index shown in Fig. 1 is calculated by this method.

Ogi et al. (2004) and Tachibana et al. (2010) demonstrated that in winter, but not in summer, the SV NAM
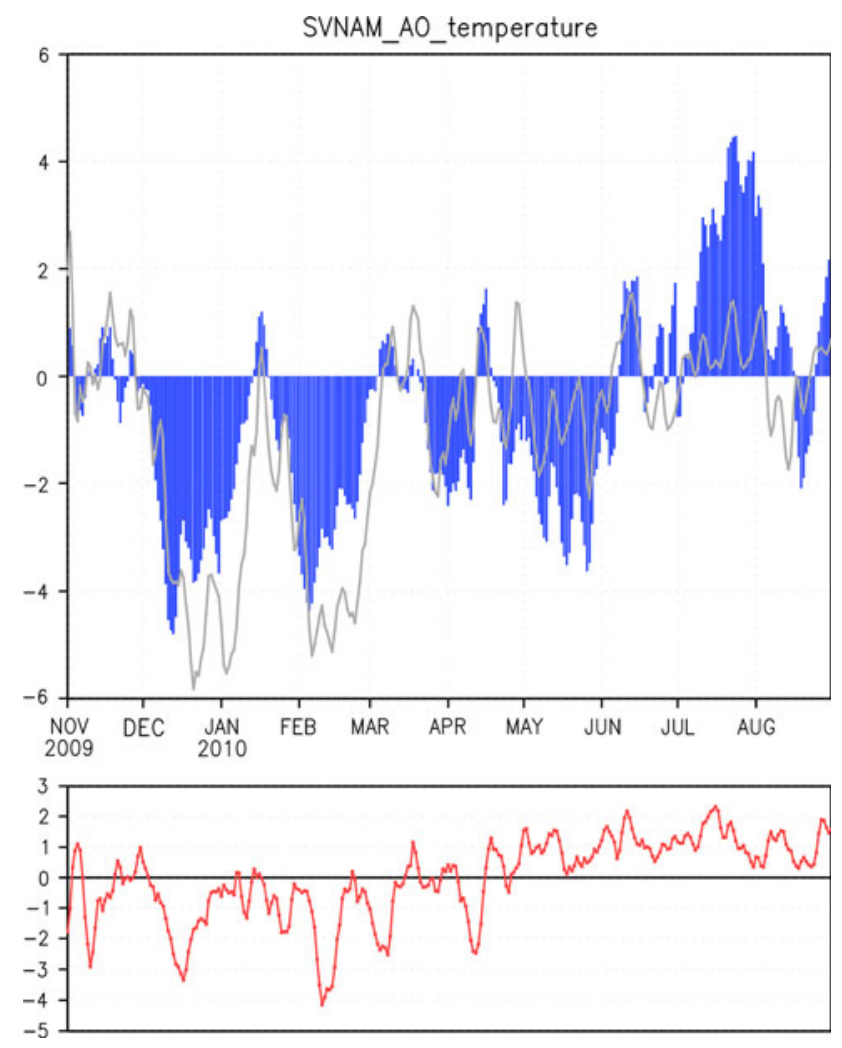

Fig. 1 (Top) Time series of the AO index (blue) as defined by Ogi et al. (2004), who called it the SV NAM index. For reference, the conventional AO index reported by NOAA/CPC is shown by the gray line. The vertical axis is dimensionless because the indices are normalized. Tick marks on the horizontal axis indicate the 1 day of each month. Updated daily time series from 1958 are available at http://www.bio. mieu.ac.jp/kankyo/shizen/lab1/AOindex.htm. (Bottom) Time series of the temperature anomaly $(\mathrm{K})$ at $925 \mathrm{hPa}$ averaged northward of $32.5^{\circ} \mathrm{N}$ over the Eurasian continent. Anomalies are calculated according to the daily climatology of 32 years

accords well with the AO defined by Thompson and Wallace (2000) and used by the Climate Prediction Center of the U.S. National Oceanic and Atmospheric Administration (NOAA/CPC). Ogi et al. (2005) and Tachibana et al. (2010) also demonstrated that the SV NAM successfully captures anomalous summertime weather conditions associated with blocking anticyclones, such as the hot summer in Europe in 2003, whereas the original AO of Thompson and Wallace (2000), mainly reflects atmospheric variabilities in winter and cannot capture such a hot summer. Therefore, Ogi et al. (2005) redefined the summertime SV NAM as the summer AO. In this study, therefore, we adopted the SV NAM index defined by Ogi et al. (2004) as the AO index, and all references to the AO index in this study mean the SV NAM index.

We used daily data of large-scale atmospheric fields from the National Centers for Environmental Prediction/ National Center for Atmospheric Research (NCEP/NCAR) reanalysis data set (Kalnay et al. 1996) to calculate the 
climatology and anomalies of the meteorological field (i.e., temperature, geopotential height, and wind velocity). Monthly means of sea surface temperature (SST) data are from the NOAA_ERSST_V3 data set, provided by NOAA/ OAR/ESRL PSD (http://www.esrl.noaa.gov/psd/) (Smith et al. 2008; Xue et al. 2003). We used monthly mean latent and sensible heat flux data of the Japan 25 year Reanalysis (JRA-25) and the JMA Climate Data Assimilation System to examine the atmosphere-ocean interaction (Onogi et al. 2007). Daily and monthly means of outgoing longwave radiation (OLR) are interpolated OLR data provided by NOAA/OAR/ESRL PSD (Liebmann and Smith 1996). Anomaly fields of individual variables are relative to the multi-year mean climatology from 1979 to 2010 for each month.

\section{Strongly positive AO days}

The winter-to-summer evolution of the AO index (Fig. 1) showed a strongly negative AO in winter 2009/2010 that lasted through May, followed by an abrupt change to strongly positive values in July and August 2010. In particular, the AO index was extremely positive from 10 July to 4 August 2010, coinciding with a period of abnormally hot days in eastern Europe and the Russian far east. Moreover, the AO index in winter and summer accords well with changes in the temperature anomaly for the Eurasian continent over the same period (Fig. 1, lower panel), although the AO index in spring did not accord well with the temperature. Time-mean atmospheric fields during the strongly positive AO period are shown in Fig. 2. The temperature anomaly field at $850 \mathrm{hPa}$ shows two obvious exceptionally hot areas, one centered over eastern Europe and the other over the Russian far east. Between these two hot areas, cold anomaly areas can be seen over central Siberia and the Arctic. At $300 \mathrm{hPa}$, a negative geopotential height anomaly is seen over the Arctic region that elongates southward toward central Siberia, whereas positive anomalies characterize the midlatitudes of the Northern Hemisphere. Over eastern Europe, Mongolia, the Russian far east, and the eastern North Pacific Ocean the positive anomalies are particularly strong. This pattern is very similar to the positive summer AO pattern observed during the unusually hot summer of 2003 (Ogi et al. 2005). In summer 2010, the geopotential height contours meandered widely around the Arctic region, indicating that the polar jet stream meandered similarly. In addition, the jet stream split into north and south branches over eastern Europe and the Russian far east, suggesting the existence of a blocking high. At $300 \mathrm{hPa}$, wave-activity fluxes (Fig. 2a, green arrows) over the polar jet were oriented from Europe to south of Alaska along the longitudinal circle, and they were particularly strong over eastern Europe and the Russian far east, suggesting Rossby wave sources in those areas. The existence of a double jet stream structure is also apparent in the two zonal wind maxima seen at about $72^{\circ} \mathrm{N}$ and $45^{\circ} \mathrm{N}$ along $135^{\circ} \mathrm{E}$ (Fig. 2c). From the surface to the upper troposphere at about $55^{\circ} \mathrm{N}$, where the largest negative wind anomaly is observed, the wind direction is easterly. This large-scale pattern in 2010 is consistent with the findings of Ogi et al. (2004), who reported an enhanced double jet in the positive phase of the summer AO.

\section{Oceanic footprint left by the previous winter's negative AO}

In the North Atlantic Ocean, a tripolar SST anomaly pattern, warm in the high latitudes, cool in the midlatitudes, and warm in the tropics, persisted from January to August 2010 (Fig. 3). This tripolar pattern is typical of a negative wintertime NAO (e.g., Rodwell et al. 1999; Tanimoto and Xie 2002). In fact, the geopotential height anomaly field at $500 \mathrm{hPa}$ in winter (DJF) 2009/2010 showed the typical pattern for the negative phase of the NAO (Fig. 4). The strong negative phase of the AO index in the winter of 2009/2010 corresponded to the negative phase of the NAO (Fig. 4a, b). The temperature anomaly at $850 \mathrm{hPa}$ of winter in the region of high-latitude and mid-latitude North Atlantic corresponded well to the total latent and sensible heat flux anomaly in January and February (Figs. 3, 4c). Similar to the tripolar SST anomaly pattern, the total latent and sensible heat flux anomaly in January and February was also tripolar (Fig. 3): a downward flux anomaly occurred over high latitudes and the tropical North Atlantic, and an upward flux anomaly was observed over the midlatitudes. The downward anomaly in the high latitudes and tropical North Atlantic lasted until April, but the sign of the latent and sensible heat flux anomaly reversed from downward to upward over the tropical North Atlantic in May and June and over the North Atlantic high latitudes in July and August, whereas the warm SST anomaly in the high latitudes and tropical North Atlantic continued into the summer. The monthly mean tropical North Atlantic SST from January to August was the warmest observed in the 32 years from 1979 to 2010 . On the strongly positive AO days, the OLR anomaly over the North Atlantic was strongly negative over the Caribbean Sea (Fig. 5). The negative OLR anomaly area, which was characterized by strong convective activity, roughly coincided with the area of the warm SST and upward sensible and latent heat flux anomalies in summer. In addition, the wind field anomaly in the lower troposphere was cyclonic in the central area of the negative OLR anomaly in the tropical North Atlantic. 
Fig. 2 a Time-mean geopotential height at $300 \mathrm{hPa}$, b temperature at $850 \mathrm{hPa}$ (T850), and c vertical cross section of the eastward wind component at $135^{\circ} \mathrm{E}$ in the Northern Hemisphere during strongly positive AO days from 10 July to 4 August 2010. Contours show time-mean values of geopotential height (a) contour interval $100 \mathrm{~m}$ ), temperature $(\mathbf{b}$, contour interval $5 \mathrm{~K}$ ), and wind speed (c, contour interval $5 \mathrm{~m} \mathrm{~s}^{-1}$ ), and the color shading shows (a) the geopotential height anomaly, (b) the temperature anomaly, and (c) the zonal wind anomaly from climatological temporal means. The green arrows in (a) show the wave activity flux $\left(\mathrm{m}^{2} \mathrm{~s}^{-2}\right)$ at $300 \mathrm{hPa}$ as formulated by Takaya and Nakamura (2001), with the scale shown by the arrow in the upper right corner (a)

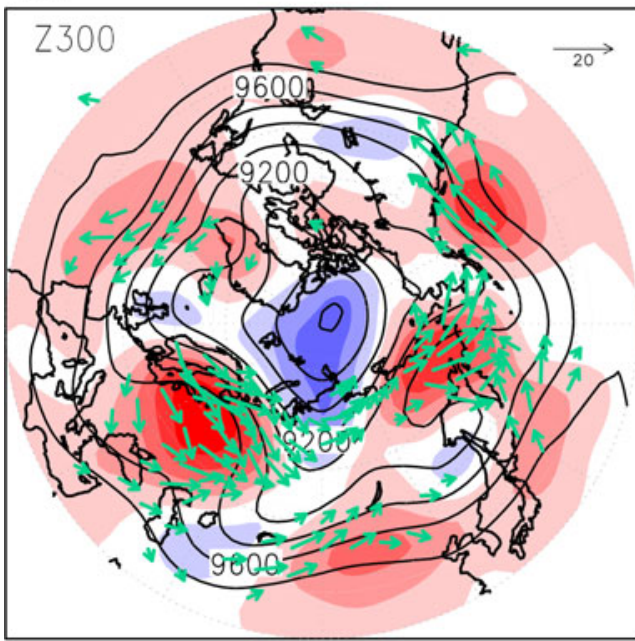

(b)

(c)
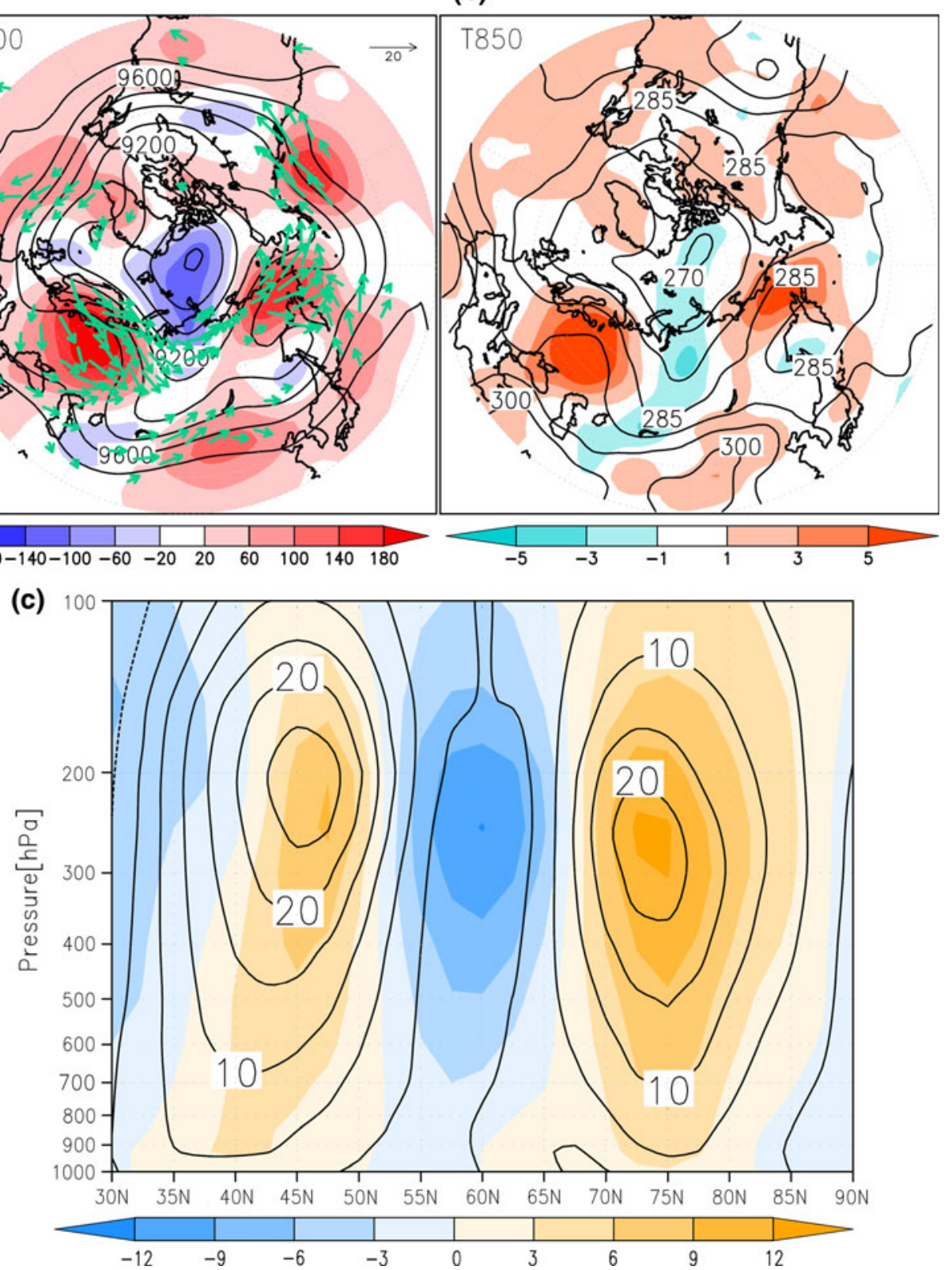

\section{Steady responses to the oceanic forcing in the Atlantic region}

The results presented in Sects. 3 and 4 suggest that the SST anomaly pattern in the Atlantic Ocean in summer 2010 remotely influenced the midlatitude atmospheric circulation. Many studies have investigated North Atlantic influences on the midlatitudes. For example, Cassou et al. (2005) showed that atmospheric convection over the tropical Atlantic leads to an anticyclonic anomaly over Europe. To make a robust assessment of the SST influence, a sensitivity experiment conducted with a numerical model that simulated the atmospheric responses to a given anomalous SST in the Atlantic region would be useful. However, it is generally difficult to simulate the evolution of a blocking high with an atmospheric general circulation model because of the strong non-linearity of blocking highs. Here we adopted instead a simple linear model, formulated by Watanabe and Kimoto (2000), to simulate the atmospheric response to the ocean. In this model, a spectral primitive equation is linearized about the climatological mean state. We used a version with T42L20 resolution. A steady response $X$ with the basic state $\bar{X}$ is derived by using an equation with the matrix form.

$L(\bar{X}) X=Q$,

where $Q$ is the temperature forcing vector and $\mathrm{L}$ is the linear dynamical operator (for details, see "Appendix 1" 

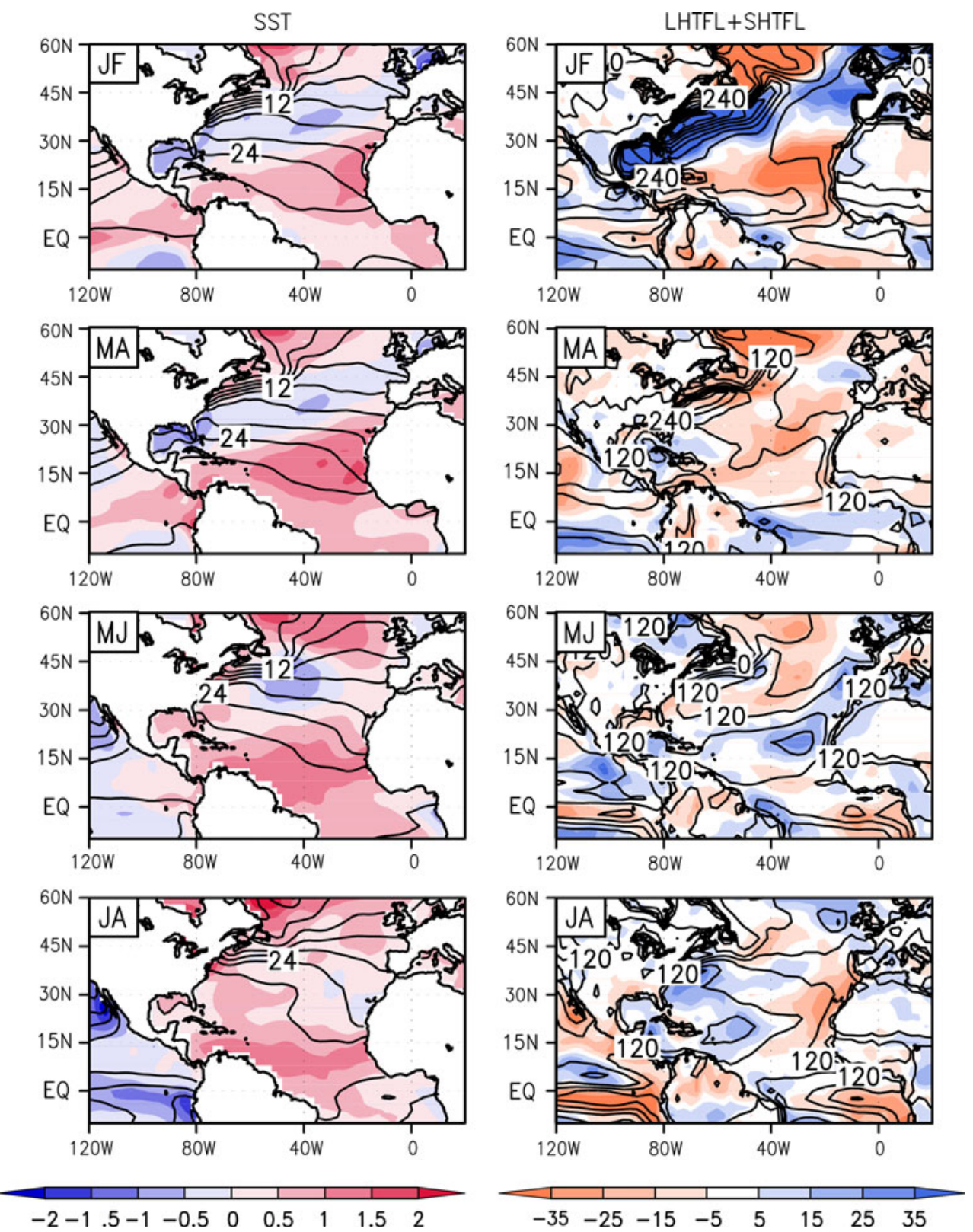

Fig. 3 Evolution of (left column) SST and its anomaly, and (right column) the sum of the latent and sensible heat fluxes and its anomaly, from January to August 2010. Contours show 2 month mean values, and the color shading shows the anomalies (deviations from the climatological temporal mean). JF, January and February;

and Watanabe and Kimoto 2000). We defined $\bar{X}$ as the climatological mean in July, derived from the monthly mean NCEP/NCAR reanalysis data set, and $\mathrm{Q}$ as the diabatic heating anomalies in July 2010, obtained by a conventional Q1 analysis (Yanai et al. 1973, see "Appendix 2 " for details) using the $6 \mathrm{~h} \mathrm{NCEP/NCAR} \mathrm{reanalysis} \mathrm{data.}$ A model simulation is useful to examine whether the oceanic memory in the Atlantic region is essential to the generation of the blocking high. Thus, we separately calculated $\mathrm{Q}$ at levels from 0.7 to $0.3 \sigma$ ( $\sigma$-coordinate system)

MA, March and April; MJ, May and June; JA, July and August. The contour interval for SST is $3{ }^{\circ} \mathrm{C}$, and that for the flux is $40 \mathrm{Wm}^{-2}$. Here, a positive flux (i.e., upward flux) is defined as from the ocean to the atmosphere. Red or blue shading in the right panels thus indicates anomalous heating or cooling of the ocean, respectively

for the Atlantic Ocean region from $90^{\circ} \mathrm{W}$ to $30^{\circ} \mathrm{E}$ (Fig. 6a) and the Eurasian and African continental region from $0^{\circ} \mathrm{E}$ to $150^{\circ} \mathrm{E}$ (Fig. 6b) in the Northern Hemisphere. The horizontal distribution of the diabatic heating anomalies in July 2010 (Fig. 6a) is acceptably similar to the SST tripolar pattern (Fig. 3, JA, bottom left). In particular, warmer SST regions (around the British Isles and near the equator) correspond to positive anomalies in the temperature forcings. The coincidence of the regions of warmer SST and positive heating anomalies indicates that the Atlantic Ocean heats the 
Fig. 4 Winter 2009/2010

(December, January, and February) mean geopotential height at $1000 \mathrm{hPa}$ (a) and $500 \mathrm{hPa}(\mathbf{b})$ and temperature at $850 \mathrm{hPa}(\mathbf{c})$. Contours show winter mean values of geopotential height (contour interval $50 \mathrm{~m}$ ) and temperature (contour interval $5 \mathrm{~K}$ ). The color shading shows the geopotential height anomaly or the temperature anomaly from climatological temporal means (a)

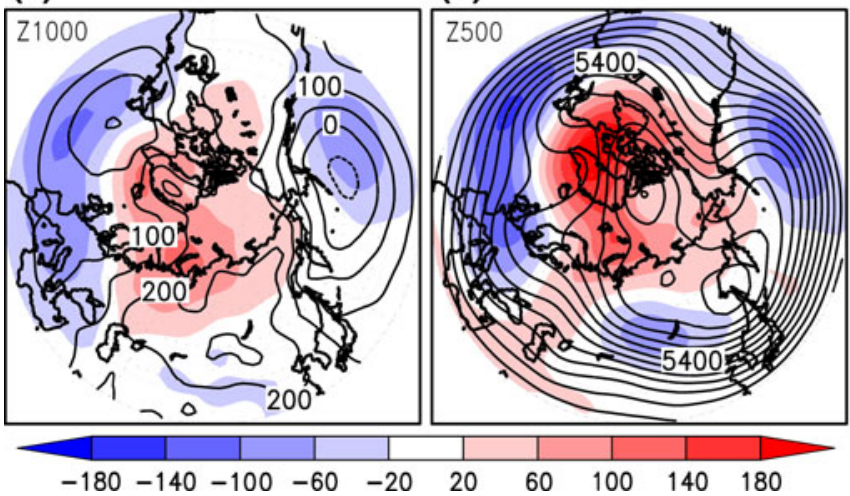

(c)

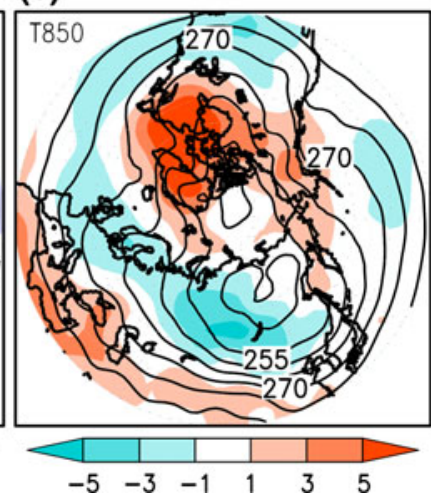

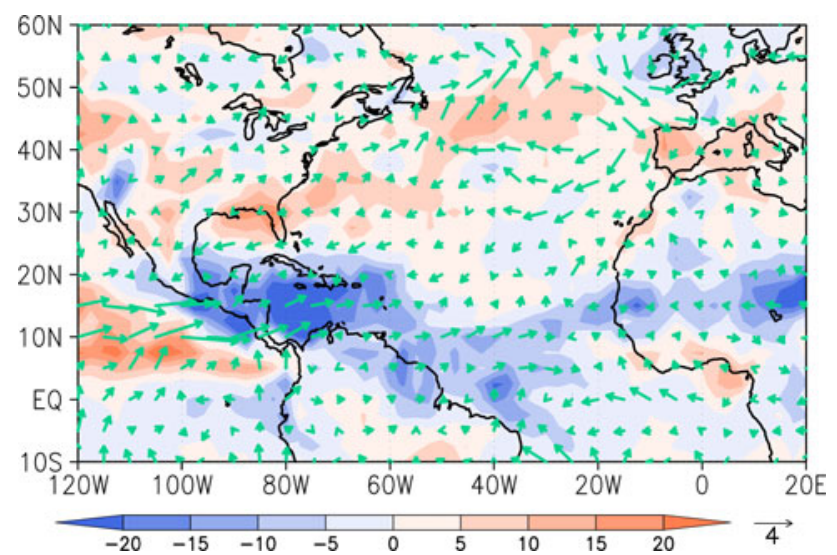

Fig. 5 OLR anomaly (color scale, $\mathrm{Wm}^{-2}$ ), defined as the deviation from the climatological temporal mean, on strongly positive AO days. Arrows show the surface wind anomaly $\left(\mathrm{m} \mathrm{s}^{-1}\right)$ on strongly positive $\mathrm{AO}$ days, with the scale shown by the arrow below the lower right corner

atmosphere in those regions. On the other hand, in the continental region, although heating anomalies are significant over low-latitude Africa where OLR anomalies were negative (Fig. 5), cooling anomalies are dominant in western Russia and northern Europe but with except of Scandinavia.

Figure 7 shows the steady responses of zonal wind and geopotential height at $300 \mathrm{hPa}$ to the given $Q$. In the responses to the forcing of the Atlantic Ocean, an anticyclonic height anomaly with a maximum amplitude exceeding $30 \mathrm{~m}$ is obvious over northern Europe (Fig. 7c), and the corresponding zonal wind anomaly strengthens the climatological double-jet structure (Fig. 7a). On the other hand, in the responses to the forcing of the Eurasian and African continent, a strong cyclonic anomaly is seen over northern Europe/western Russia (Fig. 7d), which may be a counter response to dynamical (i.e., adiabatic) heating due to the blocking high developed there. Thus, our model simulation strongly suggests that atmospheric heating related to the tripolar pattern of the Atlantic SST anomaly is one of the main causes of the blocking high over Europe. (a) JUL2010 Heating anomalies in Atl.0cn.


Fig. 6 Vertically averaged (from 0.7 to $0.3 \sigma$ ) diabatic heating derived from a conventional Q1 analysis (Yanai et al. 1973). The color scale indicates the heating anomaly $\left(\mathrm{K} \mathrm{day}^{-1}\right)$ in July 2010 (deviation from the July climatological mean). a Heating anomalies over only the Atlantic Ocean (from $90^{\circ} \mathrm{W}$ to $30^{\circ} \mathrm{E}$, from $0^{\circ} \mathrm{N}$ to $90^{\circ} \mathrm{N}$ ). b Heating anomalies over only the Eurasian and African continent (from $0^{\circ} \mathrm{E}$ to $150^{\circ} \mathrm{E}$, from $0^{\circ} \mathrm{N}$ to $90^{\circ} \mathrm{N}$ )

\section{Discussion}

Taking together the results presented in Sects. 3, 4, and 5, we suggest that an oceanic memory of the strongly negative wintertime AO may have influenced the strongly positive summertime AO. A negative wintertime NAO would cause warm SST anomalies in high- and low-latitude regions of the Atlantic, as suggested by Xie and Tanimoto (1998) and Tanimoto and Xie (2002). Because the horizontal structures of the NAO and the AO in the Atlantic sector in winter 2009/2010 are similar (See Fig. 4), the strongly negative wintertime $\mathrm{AO}$ would maintain the warm SST anomaly in this region. The 
Fig. 7 a Steady responses of zonal wind at $300 \mathrm{hPa}$ (U300) to the heating anomalies over the Atlantic Ocean, corresponding to those shown in Fig. 6a. Red/blue shading indicates positive/negative anomalies with units $\left(\mathrm{m} \mathrm{s}^{-1}\right)$. b As in (a) except for responses to the heating anomalies over the Eurasian and African continent, corresponding to those shown in Fig. 6b. (c and d) As in (a) and (b) respectively except for geopotential height at $300 \mathrm{hPa}(\mathrm{Z} 300)$ with units (m) (a) JUL2010 U300 responses to AtI.Ocn.

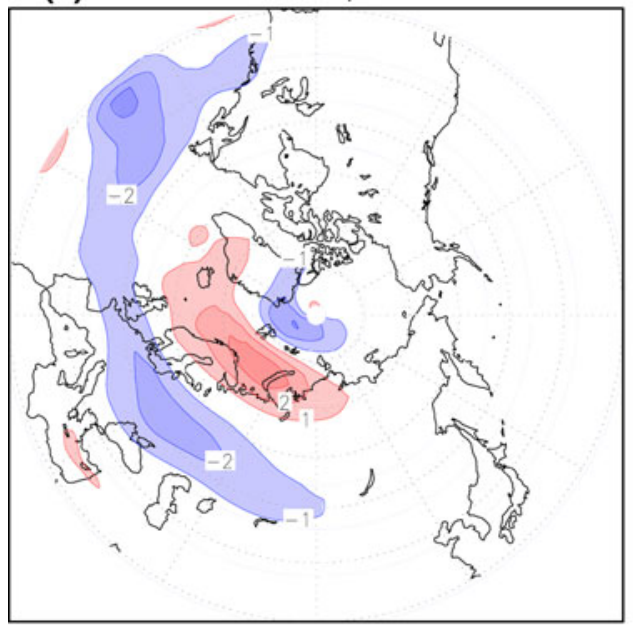

(c) JUL2010 Z300 responses to Atl.Ocn.

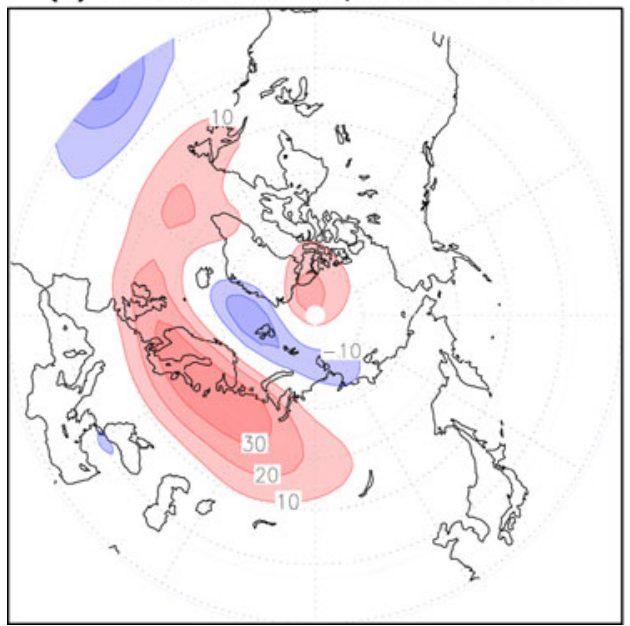

(b) JUL2010 U300 responses to Eu.+Af.Cnt.

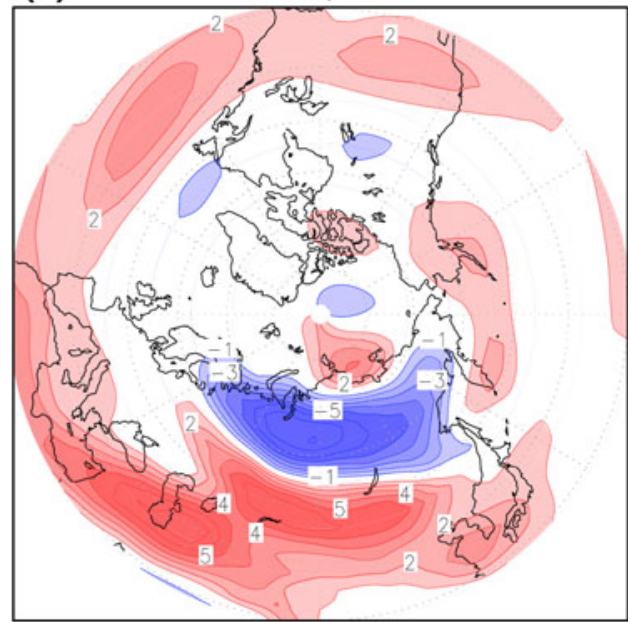

(d) JUL2010 Z300 responses to Eu.+Af.Cnt.

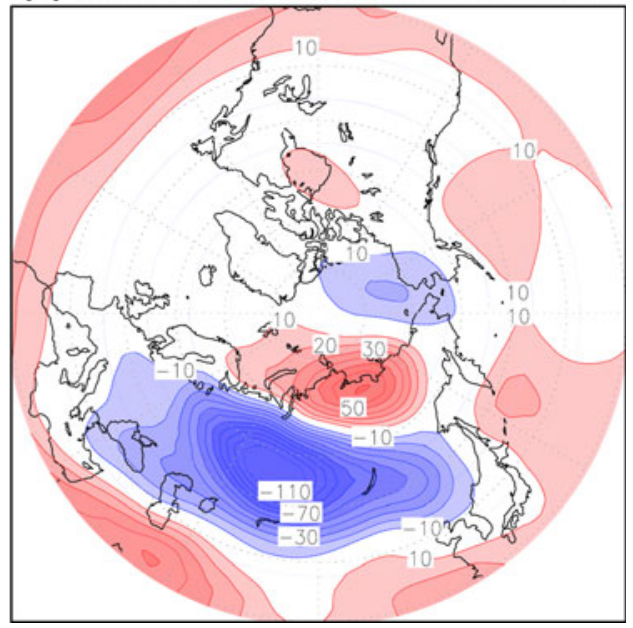

downward latent and sensible heat flux anomaly over the high latitudes and the tropical Atlantic (Fig. 3) in winter and spring indicates that anomalous heating of the ocean by the atmosphere occurred from winter to spring during the strongly negative phase of the AO in winter 2009/2010. Because the thermal heat capacity of the ocean is large, the sea surface stored this warmth (i.e., the SST anomaly remained positive) into the following summer.

In May and June, the heat flux anomaly changed from downward to upward in the tropics (see Fig. 3), and in July and August, the center of the upward anomaly moved westward. The area of the upward heat flux anomaly coincided with the area of the warm SST anomaly from May to August. The warm SST during the summer following the strongly negative wintertime AO therefore heated the atmosphere, activating atmospheric convection. The OLR anomalies also indicate high convective activity in the tropical Atlantic region (Fig. 5), suggesting a remote influence of the Atlantic SST upon the occurrence of an anticyclone over Europe. This Atlantic SST influence has been pointed out by many studies (e.g., Cassou et al. 2005;
García-Serrano et al. 2008). García-Serrano et al. (2008) showed that a midlatitude anticyclonic anomaly related to tropical convection can excite a Rossby wave. Our numerical experiment using the linear model showed that the atmospheric response to the tripolar SST pattern clearly resulted in an anomalous height and wind pattern that caused a blocking high over Europe (Figs. 6, 7), however, the modeled geopotential amplitude is weaker than the observations. This discrepancy is because a linear model cannot represent the dynamical instability due to, for example, wave-wave interaction. Therefore, the model indicates that although the oceanic memory in the Atlantic is a trigger, by itself it is insufficient to cause a blocking high to develop. Weak, positive OLR anomalies along the Gulf Stream were associated with anticyclonic surface winds on strongly positive AO days (Fig. 5). The observed wave activity flux (Fig. 2a) also seems to emanate from that region. This midlatitude signature implies that strengthening of the positive geopotential anomalies over Europe was associated with the Atlantic tripolar SST anomaly. 
The positive geopotential anomaly in the area of the polar jet stream caused eastward propagation of Rossby waves, and the unusual amplification of Rossby waves might have led to the formation of blocking anticyclones. These findings are in agreement with previous studies. For example, Tachibana et al. (2010) reported that a blocking anticyclone over the Atlantic sector that induces blocking over the Russian Far East is associated with a long-lasting, strongly positive AO caused by wave-mean flow interactions. As a result of these interactions, the positive AO pressure pattern can continue for a long time. In addition, Orsolini and Nikulin (2006) pointed out that the blocking anticyclone over Europe in summer 2003 was part of a wave train extending from Europe to eastern Eurasia. The linear model did not simulate an anticyclonic anomaly in the Russian Far East. To simulate the influence of an anomalous wintertime negative $\mathrm{AO}$ on an anomalous positive $\mathrm{AO}$ in the following summer due to a long-lasting oceanic memory, an atmosphere-ocean coupled high-resolution model simulation is needed. We reserve this experiment for future studies.

Of course, the set of processes introduced here is just one possible explanation for the formation of the strongly positive summer AO in 2010. For example, summertime SST anomalies in the Mediterranean Sea (Feudale and Shukla 2010) might simultaneously induce a strongly positive summer AO. Although the effect of the oceanic memory of a negative AO during the previous winter might be smaller than the effects of simultaneous events, the previous winter's footprint may at least play a role in the reversal of the AO polarity from a strongly negative wintertime $\mathrm{AO}$ to a strongly positive summertime AO. If this reversal pattern recurs, it might be possible to predict the summer $\mathrm{AO}$ from the wintertime $\mathrm{AO}$. The more negative the winter $\mathrm{AO}$ anomaly is, the deeper the footprint left in the ocean would be, suggesting that a winterto-summer reversal of the AO might occur only in years when the negative wintertime $\mathrm{AO}$ anomaly is large. In addition to an oceanic memory effect, other memory effects such as anomalous snow accumulation on the Eurasian continent or elsewhere in the Northern Hemisphere, as suggested by Ogi et al. (2003) and Barriopedro et al. (2006), may also contribute to the reversal of AO polarity. To test these possibilities, statistical analyses of multi-year data and simulation by a full coupled atmosphere-ocean-land global climate model are the next step.

Acknowledgments We extend special thanks to V. A. Alexeef, M. Honda, H. E. Hori, and J. Inoue for their very helpful comments on this study. We also thank two anonymous reviewers for their valuable comments and suggestions to improve the quality of the paper. This study was supported by Grant-in-Aid for challenging Exploratory Research 22654055, and a part of this study was supported by "Green Network of Excellence" Program (GRENE Program) Arctic Climate Change Research Project.
Open Access This article is distributed under the terms of the Creative Commons Attribution License which permits any use, distribution, and reproduction in any medium, provided the original author(s) and the source are credited.

\section{Appendix 1: A brief description of the linear baroclinic model}

In this study, we used a linear baroclinic model (LBM) identical to one used by Watanabe and Kimoto (2000). They exactly linearized primitive equations in which the

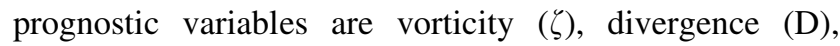
temperature $(\mathrm{T})$, and surface pressure $\left(\pi=\ln P_{s}\right)$. Using a state vector $X(\zeta, D, T, \pi)$, a dynamical system can be represented as.

$d_{t} X+(L+N L) X=F$,

where $\mathrm{L}$ and $\mathrm{NL}$ are the linear and nonlinear parts of a dynamical operator that consists of, for example, advection, Coriolis, pressure gradient, and dissipation terms. $\mathrm{F}$ is a forcing (in this study, we used diabatic heating $\mathrm{Q}$ ). Now, a state vector $\mathrm{X}$ can be decomposed into a basic state $\bar{X}$ and a perturbation part $X^{\prime}$, i.e., $X=\bar{X}+X^{\prime}$. Equation (1) is linearized about a basic state $\bar{X}$. Then we consider the steady problem, neglecting the nonlinear part, obtaining a set of linear equations for the perturbation of the prognostic variables $X^{\prime}$ :

$L X^{\prime}=F^{\prime}$.

Note that a linear dynamical operator $L$ is now a function of the basic state, i.e., $L \equiv L(\bar{X})$, obtained following Hoskins and Karoly (1981). Equation (2) can be solved by using an inverse matrix of $L$ :

$X^{\prime}=L^{-1} F^{\prime}$

Equation (3) gives us a steady response to a given forcing. Linearized equations are not necessarily required to obtain a steady response. For a process such as the development of a blocking high, in which internal instability is important, linear responses may be weaker than expected. However, LBM is useful for diagnosing the primary response of the atmosphere without secondary feedback due to, for example, changes in heat fluxes from surfaces.

\section{Appendix 2: Estimation of diabatic heating in the atmosphere}

Atmospheric diabatic heating can be estimated as a residual term from a heat budget analysis of the thermodynamical 
equation. Here, diabatic heating $Q$ is defined as follows: $Q \equiv C_{p}\left(p / p_{0}\right)^{\frac{R}{C_{p}}}\left(\frac{\partial \theta}{\partial t}+v \cdot \nabla \theta+\omega \frac{\partial \theta}{\partial p}\right)$, where $C_{p}$ is specific heat of dry air at constant pressure, $R$ gas constant for dry air, $p$ pressure, $p_{0}$ standard sea level pressure (= $1,000 \mathrm{hPa}$ ), $\theta$ potential temperature, $v$ horizontal wind vector, and $\omega$ pressure velocity. $Q$ includes not only sensible heat but also latent and radiative heat. In general, in the free troposphere, the latent heat associated with the condensation and the evaporation of water vapor is dominant, although the radiative heating may be large in a specific situation such as at the cloud-top.

This estimation method was first introduced by Yanai et al. (1973). They used $Q$ (named Q1 in their study) as an apparent heat source and further defined Q2, which is a residual term of the water vapor budget equation, as an apparent moisture (i.e., latent heat) sink to estimate properties of the tropical cloud cluster from the observed largescale heat and moisture budget. They also pointed out that this method is useful for determining how a large-scale air is heated diabatically, including both latent and radiative heating.

\section{References}

Barriopedro D, García-Herrera R, Hernández E (2006) The role of snow cover in the Northern Hemisphere winter to summer transition. Geophys Res Lett 33:L14708. doi:10.1029/2006GL0 25763

Barriopedro D, Fischer EM, Luterbacher J, Trigo RM, García-Herrera R (2011) The hot summer of 2010: redrawing the temperature record map of Europe. Science 332:220-224. doi:10.1126/science. 1201224

Cassou C, Terray L, Phillips AS (2005) Tropical Atlantic influence on European heat waves. J Clim 18:2805-2811

Cattiaux J, Vautard R, Cassou C, Yiou P, Masson-Delmotte V, Codron F (2010) Winter 2010 in Europe: a cold extreme in a warming climate. Geophys Res Lett 37:L20704. doi:10.1029/2010GL 044613

Feudale L, Shukla J (2010) Influence of sea surface temperature on the European heat wave of 2003 summer. Part I: an observational study. Clim Dyn 36:1691-1703. doi:10.1007/s00382-010-0788-0

García-Serrano J, Losada T, Rodríguez-Fonseca B, Polo I (2008) Tropical Atlantic variability modes (1979-2002). Part II: timeevolving atmospheric circulation related to SST-forced tropical convection. J Clim 24:6476-6497

Hoskins BJ, Karoly DJ (1981) The steady linear response of a spherical atmosphere to thermal and orographical forcing. J Atmos Sci 38:1179-1196

Kalnay E et al (1996) The NCEP/NCAR 40 year reanalysis project. Bull Am Meteorol Soc 77:437-471
Liebmann B, Smith CA (1996) Description of a complete (interpolated) outgoing longwave radiation dataset. Bull Am Meteorol Soc 77:1275-1277

Matsueda M (2011) Predictability of Euro-Russian blocking in summer of 2010. Geophys Res Lett 38:L06801. doi:10.1029/2010GL 046557

Ogi M, Yamazaki K, Tachibana Y (2003) Solar cycle modulation of the seasonal linkage of the North Atlantic Oscillation (NAO). Geophys Res Lett 30:2170. doi:10.1029/2003GL018545

Ogi M, Yamazaki K, Tachibana Y (2004) The summertime annular mode in the Northern Hemisphere and its linkage to the winter mode. J Geophys Res 109:D20114. doi:10.1029/2004JD004514

Ogi M, Yamazaki K, Tachibana Y (2005) The summer northern annular mode and abnormal summer weather in 2003. Geophys Res Lett 32:L04706. doi:10.1029/2004GL021528

Onogi K et al (2007) The JRA-25 reanalysis. J Meteorol Soc Japan 85:369-432

Orsolini YJ, Nikulin G (2006) A low-ozone episode during the European heatwave of August 2003. Quart J R Meteor Soc 615:667-680. doi:10.1256/qj.05.30

Rodwell MJ, Rowell DP, Folland CK (1999) Oceanic forcing of the wintertime North Atlantic Oscillation and European climate. Nature 398:320-323

Smith TM, Reynolds RW, Peterson TC, Lawrimore J (2008) Improvements to NOAA's historical merged land-ocean surface temperature analysis (1880-2006). J Clim 21:2283-2296

Tachibana Y, Nakamura T, Komiya H, Takahashi M (2010) Abrupt evolution of the summer Northern Hemisphere annular mode and its association with blocking. J Geophys Res 115:D12125. doi: 10.1029/2009JD012894

Takaya K, Nakamura H (2001) A formulation of a phase-independent wave-activity flux for stationary and migratory quasigeostrophic eddies on a zonally varying basic flow. J Atmos Sci 58:608-627

Tanimoto Y, Xie SP (2002) Inter-hemispheric decadal variations in SST, surface wind, heat flux and cloud cover over the Atlantic Ocean. J Meteor Soc Japan 80:1199-1219

Thompson DWJ, Wallace JM (2000) Annular modes in the extratropical circulation. Part I: month-to-month variability. J Clim 13:1000 1016

Trigo RM, García-Herrera R, Díaz J, Trigo IF, Valente MA (2005) How exceptional was the early August 2003 heatwave in France? Geophys Res Lett 32:L10701. doi:10.1029/2005GL022410

Wang L, Chen W (2010) Downward Arctic Oscillation signal associated with moderate weak stratospheric polar vortex and the cold December 2009. Geophys Res Lett 37:L09707. doi: 10.1029/2010GL042659

Watanabe M, Kimoto M (2000) Atmosphere-ocean thermal coupling in the Northern Atlantic: a positive feedback. Quart J R Meteorol Soc 126:3343-3369

Xie SP, Tanimoto Y (1998) A Pan-Atlantic decadal climate oscillation. Geophys Res Lett 25:2185-2188

Xue Y, Smith TM, Reynolds RW (2003) Interdecadal changes of 30 year SST normals during 1871-2000. J Clim 16:1601-1612

Yanai M, Esbensen S, Chu JH (1973) Determination of bulk properties of tropical cloud clusters from large-scale heat and moisture budgets. J Atmos Sci 30:611-627 